\title{
The Role of Decision Support Systems in the Re-Engineering of Administrative Processes in Saudi Higher Education Institutions - Taif University Case Study
}

\author{
Dr. Adnan Awwad AL - Shawabkeh \\ Department of Management Information Systems (MIS) \\ Taif University
}

\begin{abstract}
The aim of this study is to identify the role of decision support systems (DSS) in the Re-engineering of administrative processes at Taif University. To achieve the objectives of the study, a questionnaire was designed and developed covering (30) items for the purpose of collecting and distributing the data among the members of the sample of which comprises (75) employees. Therefore, data were collected, analyzed and tested using SPSS. Numerous statistical methods were used to achieve the study objectives including the analysis of multiple and simple regression. After conducting the analysis of the study data and hypotheses, the study concluded several results; the most noticeable are:
\end{abstract}

1. The decision support systems (DSS) in the Re-engineering of administrative processes have an impact in supporting senior management to use high resolution support systems.

2. The level of available requirements (hardware, software, human and organizational) is high.

3. The level of the type of used decision support systems is high.

4. The level of senior management support for the use of decision support systems (DSS) and available requirements (hardware, software, human and organizational) and the type of used decision support systems is high.

5. There is a statistically significant relationship at the level of $\alpha \leq 0.05$ between (senior management support, hardware, software, human and organizational requirements and the type of decision support systems) for the use of decision support systems (DSS) and Re-engineering processes.

6. There are no statistically significant differences between the responses of the respondents at the level of $\alpha \leq$ 0.05 on the role of decision support systems in the Re-engineering of administrative processes at Taif University due to the variables of age, qualification and functional experience.

\section{The study recommended the following:-}

1. Developing IT infrastructure in general and decision support systems in particular.

2. Increasing the attention to the hardware and software requirements available to use decision support systems through sustainable modern technologies.

3. Increasing the attention to the human requirements available to use decision support systems by providing specialized training programs for administrators and academics.

4. Increasing the attention to the organizational requirements available to use decision support systems through an independent unit of decision support systems that is directly affiliated with the university administration.

5. Connecting computers in the university with the other administrations through a communication network, as well as linking the university units and administrations with the internet and activating the web programs.

\section{Introduction}

Over the past years, there have been many developments and challenges that have had direct effects on the public sector. The most important of these challenges are the different role of the country in community, environmental changes, privatization and the development of (ICTs). In order for the public sector to be able to cope with such economic, technological and environmental changes, recent developments in management should be made use of to deal with such changes and developments. Dealing with the changes that occur at the local, regional and global level requires the need to bring about radical changes in the management method of the educational institutions and their provision of services. This requires the adoption of modern management methods adapted to the changes that the public sector undergoes. Traditional management methods are no longer capable of dealing with recent developments. 
Re-engineering processes is considered one of the most prominent modern administrative phenomena that emerged in the early nineties. The consolidation of critical success factors (CSFs) is regarded one of the key fields of research and study in the field of Re-engineering. Several studies have focused on the importance of the availability of many elements needed for the successful implementation of a private sector for the Re-engineering program, while those studies have overlooked the public sector. The availability of critical success factors is vital to the success of the Re-engineering project. Thus, ensuring the availability of critical factor requirements is a regulatory requirement for the Re-engineering project. As many government agencies adopt the concept of Reengineering administrative processes, there is an urgent need to identify the basic requirements for the application of Re-engineering of administrative processes in the public sector (Hammer, 2012).

The dependence of the administration of educational organizations on the Re-engineering of administrative processes is a real crisis for this administration. The first crisis is related to administrative efficiency, such as the scarcity of quality decisions, the lack of partaking in decision making, the lack of cooperation between members of the educational community and the complexity of the work procedures. The second one is related to the quality of the educational processes itself. This is a logical result due to the poor investment of human and hardware resources, inefficiency, poor time management and preference of the individual interest to the public one. The third one is concerned with the low ability of educational institutions to prepare graduates to suit the requirements of the labor market, inn addition to poor distribution of information among all administrative organizations.

\section{The Problem of the study :}

Developed countries have resorted to one of the administrative approaches which is basically based on radical and fundamental change in the development of their educational institutions. They relied on Re-engineering administrative processes in order to face the challenge of competition, reduce costs, balance the budget and determine the future of the university in the $21^{\text {st }}$. century. Thus, leading to the achievement of their universities for the required effectiveness and asserting the need for information technology and human resources to achieve this effectiveness (Mustafa, 2010).

Taif University faces many difficulties and problems, most notably are the weakness of creativity, the lack of using technology in various administrative and educational activities, the weakness of transferring and circulating information and delivering it to decision-makers accurately and quickly and in a timely manner, and the weak involvement of employees in decision-making.

Therefore, it is necessary to take advantage of computerized management information systems, i.e. decision support systems, because they have the effect of increasing the speed of decision making, improving the quality of control and supervision and improving the quality of service, its speed, variety and versatility. The Reengineering approach emphasizes that the low performance of the work is mainly due to the performance of work in traditional ways, and that Re-engineering is based on the general principle which claims that educational and non-educational systems succeed or fail due to the nature of design (Althobaiti, 2012).Based on the above, the problem of the study can be formulated in the following main question :-

\section{What role do decision support systems play in Re-engineering administrative processes at Taif University?}

\section{Study Questions :}

1. What is the role of senior management support for the use of decision support systems (DSS) in Reengineering processes at Taif University?

2. What is the role of the available requirements (hardware, software, human and organizational) for the use of decision support systems (DSS) in the Re-engineering of administrative processes at Taif University?

3. What are the types of decision support systems (DSS) used at Taif University?

4. Are there statistically significant differences between the responses of the respondents at the level of $\alpha \leq 0.05$ on the role of decision support systems in Re-engineering processes at Taif University which could be ascribed to the personal and functional variables?

\section{Study Objectives :}

This study aims to achieve the following at Taif University:

1. Highlighting the importance of decision support systems and their role (DSS) in Re-engineering administrative processes. 
2. Stating the relationship of senior management support to the use of decision support systems (DSS) in the Reengineering of administrative processes.

3. Identifying the relationship of the available requirements (hardware, software, human and organizational) to the use of DSS in the Re-engineering of administrative processes.

4. Identifying the types of DSS used in the Re-engineering of administrative processes.

5. Determining the relationship between personal and functional variables (age, qualification and professional experience) and decision support systems (DSS) in the Re-engineering of administrative processes.

\section{The importance of study :}

\section{The importance of the study stems from the following factors :}

1. It is a new subject, as it is considered new according to the knowledge of the researcher, which deals with the study of the role of decision support systems (DSS) in Re-engineering processes at Taif University.

2. Drawing the attention of the management of Taif University to the importance of the notion of decision support systems (DSS) and the importance of their use, and highlighting the strengths and weaknesses resulting from their use.

3. The urgent need to raise the level of the university's performance, rationalize its financial and human resources, improve its services, and address the imbalance and causes of waste in financial and human resources, effort and time in redesigning administrative processes.

4. Enriching the Arab Library and Science Research Centers. This study provides a database to assist researchers in this field due to the shortage of previous studies in the subject of research and encouraging them to conduct further researches in this field.

\section{The hypotheses of the study :}

\section{The first main hypothesis:}

There is no statistically significant relationship at the level of $\alpha \leq 0.05$ between decision support systems (DSS) in the Re-engineering of administrative processes at Taif University.

\section{The second main hypothesis :}

There is no statistically significant relationship at the level of $\alpha \leq 0.05$ between the combined available requirements (hardware, software, human and organizational) and the use of decision support systems (DSS) in the Re-engineering of administrative processes at Taif University.

\section{The third main hypothesis :}

There is no statistically significant relationship at the level of $\alpha \leq 0.05$ for the types of decision support systems (DSS) used in the Re-engineering of administrative processes at Taif University.

\section{The fourth main hypothesis :}

There are no statistically significant differences between the responses of the respondents at the level of $\alpha \leq 0.05$ on the role of decision support systems in the Re-engineering processes at Taif University due to the personal variables (age, qualification and professional experience).

\section{Literature Review :}

\section{Theoretical framework and previous studies :}

Decision support systems are considered one of the most advanced applications of computerized information systems. Perceptions have been made regarding the possibility of a computer-based information system which is capable of serving the needs of senior management into becoming tangible. The rapid development of the production of ready programs to support the senior management helped to spread the use of these systems in organizations. It should be noted here that the senior management support systems were known in the early stages as the senior management information systems, but the senior management support systems not only provide information but also expand to include all types of senior management supports (by automating the office, electronic communication, data and forms analysis, and knowledge). In addition to providing them with internal and external information provided by the information system of the influential, where the latter allows managers to produce and see information from different dimensions. Besides, it equips managers with flexible facilities that help create more than one perspective, and create more than one view of information easily (Hammer \& Schambi, 2012). 


\section{Decision Support System (DSS) :}

Decision support systems are information technology tools used to facilitate decision-making tasks which require considerable effort and in-depth analysis. They are, therefore; responsible for performing the task of creating information related to decision-making and communicating decisions to users. The (DSS) are flexible and userfriendly IT systems, designed to support decision makers in an uncertain and unstructured environment. Electronic spreadsheet software is one of the most common examples and use of decision support systems (AlShawabkeh, 2015).

\section{The concept and importance of decision support systems (DSS) :}

Decision support systems (DSS) in rely on interactive support using a software package that allows the decision maker to deal directly with the computer to obtain effective information in the process of structured and semistructured decision-making. They are computerized information systems that assist decision-makers in solving management problems, making unstructured or semi-structured decisions, and administrative and strategic decisions.

Decision support systems have been defined as : interactive information systems that provide managers with information, models and data processes tools that help them make semi-structured and unstructured decisions in circumstances where no one knows exactly what decision to take, it is also a system capable of supporting data analysis and presenting particular models with particular themes, and directed toward strategic and long-term planning (Hamidi, 2009).

\section{According to (Bernard, 2009), the importance of decision support systems is as follows:}

1. Most of the decisions made at the senior management level are characterized by weak structural clarity. In such cases, reports resulting from functional (ISs) are of little use, hence there is a need to search for (ISs) that can help clarify the structure of the problem.

2. Senior management focuses most on dealing with the factors and areas affecting the competitive strength of the organization. The strength of this competitive position depends on the opportunities and threats in the external environment of the organization and the strengths or weaknesses of its internal environment.

3. Senior management needs information systems to help them analyze unexpected problems and make appropriate decisions.

4. Decision support systems help conduct a rapid and effective analysis of events and processes and their potential, even in emergency cases, for appropriate decision making.

5. Supporting managers in semi-structured and unstructured decision making.

\section{Components of Decision Support System (DSS) :}

\section{According to (Yassin, 2006), decision support systems consist of the following elements :}

\section{First : Decision Support System Database.}

The importance of a database is to reduce data redundancy and ease of access, taking into account database security along with a backup to ensure that processes are not interrupted when the original base is exposed to problems, and used to retrieve the data needed for decision making in the organization (Alsabbagh, 2000).

\section{Second : Data Base Management Systems (DBMS).}

Database management systems are an intermediary between the user and the databases, without which the logical structure of files and records cannot be controlled. Data cannot be modified, updated, processed and stored (Gupta, 2000).This system is used to improve the quality of database response to the system, which requires features and capabilities in database management systems to perform query, update, storage, retrieval, data process, report production and decision-making.

\section{Third: Model-Base.}

It is a package of analytical, mathematical, statistical and other models that enable the beneficiary to deal with the problem, represent it in a model and analyze it. It is also considered a storage of different decision models that vary in comprehensiveness and complexity. There are simple and straightforward mathematical decision models, and complex and difficult models related to strategic planning problems and project management. For example, models can be categorized into strategic models used to support senior management decisions, and operational models used to support structured decisions at the operational management level (Hamidi, 2009). 


\section{Fourth: Decision Support System Software System.}

Ii is a set of ready-made software packages or analytical and mathematical models used to analyze data through a set of mathematical and analytical models, instant analytical processes and data search. They contain useful models for data analysis purposes. They also provide decision alternatives; it manages a series of analyses that answer the question what-if, the use of statistical analysis tools, sensitivity analysis, targeting analysis, and optimization analysis (Alter, 2002).

\section{Fifth: Interface (Dialogue) System - User Interface.}

It is a part of the information system representing devices and a set of commands on the screen that enables the user to interact with the system. It represents the interface where the dialogue between the user and the decision support system takes place. It is represented in how to enter commands, receive inquiries, extract and analyze information using the model base (Haag, 2002).

The affecting dimensions on decision support systems :

Decision support systems are influenced by a set of variables that comprise these systems and affect and are affected by them; including the following :

1. Senior management support to use decision support systems (DSS).

2. The available hardware, software, human and organizational requirements to use decision support systems (DSS).

3. Types of used decision support systems (DSS).

\section{Re-engineering of administrative processes:}

\section{The concept of Re-engineering of administrative processes:}

The concept of Re-engineering of administrative processes first appeared in 1990, when MIT conducted a research entitled "Management in 1990." The purpose of this research was to identify the role that IT plays in business organizations. This approach is based on rejecting and changing the concepts, rules and assumptions on which the administration builds its decision, and the search for new rules, hypotheses and concepts of administrative thought that fit the twenty-first century (Hamer, 2009).

Re-engineering processes : is the rethinking, studying, examining and analyzing the flow of activities and information that comprise the core processes of the organization, with the aim of radical and rapid redesign of the organization's manufacturing and management processes, as well as the systems, policies and organizational structures supporting these processes, to eliminate any work that adds no value, improve workflow and reduce the operation time cycle, and achieve flexibility and speed of work by using advanced (IT) as a key enabling factor that allows institutions and organizations to reengineer their implementation systems (Kasasbeh, 2004).

\section{The main objectives of the Re-engineering of administrative processes :}

The objectives of the Re-engineering of administrative processes vary from one organization to another according to the circumstances of each organization and the type of work it performs. The proper Re-engineering of processes will enable the organization to achieve a set of objectives in which the processes are reengineered in organizations. According to Althobaiti (2012).

\section{These objectives can be identified as follows :}

1. Achieving a radical change in performance and processes; i.e. to change the method and tools of work by enabling employees to design work and do it according to the needs of customers and the objectives of the organization.

2. Directing the organization to focus on customers by identifying their needs and working to achieve their desires, so that the processes are reconstructed to achieve this goal.

3. Enabling the organization to do its work quickly by providing information for decision making and accessibility.

4. Improving the quality of services it provides to fit the needs of service recipients at low cost as possible.

5. Reducing cost by eliminating unnecessary processes and focusing on value added processes. 


\section{The importance of Re-engineering administrative processes :}

Re-engineering of administrative processes brings many benefits to the organization efficiently and effectively, and maintains the survival and continuity of administrative regulations to face new challenges. Many benefits and positive returns can be derived from the Re-engineering processes and changes that occur when companies are scarce and include the following (Hammer \& Schambi, 2012) :

1. The transformation of business units from functional to operation teams : Collecting specialized work by providing specific services in one place, and turning the units of work under this concept from specialized functional units to operational teams.

2. Transforming functions from simple tasks into complex ones : This method consolidates efforts, and the accountability of the performance team is also done collectively. This concept leads to the cohesion of the group because of the common goal of increasing the level of collective performance to reduce organizational structure conflicts among team members.

3. The organization is transformed from hierarchical to horizontal : When task forces are formed to carry out tasks and duties, decision-making processes and responsibilities are transferred to the task force rather than to the administrations that need to hold numerous meetings to make such decisions. This means authorizing, in accordance with the concept of Re-engineering processes, individuals who are competent in the work performance which entails the need to abolish hierarchical administrative levels and use what is known as the simplified administrative organization, which works to keep the organizational structure stable and horizontal because the work teams operate freely and independently (Alkurdi, 2013).

\section{Techniques used in Re-engineering of administrative processes :}

Among the techniques used in the Re-engineering of administrative processes are the following (Alsulami, 2009):

1. Computer technology and common databases that are adopted to provide information to all parties.

2. Decision support systems which are used to expand areas of decision-making.

3. Expert systems that help individuals to perform their work in a specialized way and communication systems to support communication between employees.

\section{Re-engineering of administrative processes and their applications in higher education institutions :}

In light of the challenges of globalization, higher education requires the Re-engineering of administrative processes in terms of direction, quality, financing, its relations to the economy via the Internet and information technology, and the development of studies, participation, education and training, and should, therefore; be based on the following foundations (Alharbi, 2008):

1. Effective and independent decisions that are taken away from bureaucratic practices and decentralization of decisions.

2. Flexibility to introduce changes.

3. Academic accountability and evaluation of academic and research achievements.

There is a need to reengineer university education as a result of the deterioration in the level of some institutions of higher education, where no single Arabic university was ranked in the list of top 200 universities according to the report issued on October 1, 2009. In addition, it is due to the failure to achieve the desired mutations in performance through the application of total quality management as well as the need to reduce the cost of educational service while maintaining quality under competitive pressures worldwide (Alharbi, 2008).

\section{Steps of Re-engineering of administrative processes in the institutions of higher education :}

Basic steps for Re-engineering processes in university education are as follows (Box , 2013) :

1. Setting goals clearly.

2. Understanding the current operation which should be quantified.

3. Typical performance through which one discovers what is the best in each area of the processes, and then the objectives are determined for the reengineered process which usually aims at better performance.

4. Identifying alternatives and proposals for redesigning the process and comparing it to the current process in view of its ability to achieve the selected objectives and alternatives. 


\section{Literature reviews:}

There are many studies that dealt with the subject of decision support systems and Re-engineering of administrative processes. A review was carried out on what was written in the administrative literature reviews and previous studies, either directly or indirectly. Some of the previous Arabic and foreign studies, that the researcher could obtain, and which are relevant to the subject of the current study, will be presented, namely :-

Malakawi (2014): Examining the impact of decision support systems and business intelligence and their impact on improving decision making at King Abdullah University Hospital. The aim of the study was to identify the decision support systems and the business intelligence systems and their impact on improving the decision making processes at King Abdullah University Hospital. In order to achieve the objectives of the study, a questionnaire was developed comprising three parts. The first part aimed at identifying the personal data related to the study sample, the second part measured the decision support systems and business intelligence, while the third part measured the level of decision making processes in King Abdullah University Hospital. The study concluded a number of results, the most important of which are:

1. Decision support and business intelligence systems have a high degree of efficiency, and the level of decision making is very high.

2. The existence of a positive correlation and of a statistical significance between decision support systems and business intelligence decision making processes.The study recommended the need to focus on decision support and business intelligence systems to improve the decision-making processes, as well as more research to be done on decision support and business intelligence systems and their role in organizations in the health sector and other sectors.

Ramadan (2010): The impact of the use of decision support systems on the development of performance: An applied study on the Ministry of Education in the governorates of the Gaza Strip. The study aimed at finding out the impact of using (DSS) on the development of performance on the Ministry of Education in the Gaza Strip governorates. The researcher designed a questionnaire for this study and distributed it to 230 employees. The study concluded a number of results, the most important of which are :

1. There is an impact of decision support systems on performance development in terms of the existence of awareness among senior management of the use of good (DSS).

2. Providing the hardware and technical resources to use the (DSS) at an average degree.

3. Providing the human resources to use the (DSS) in the ministry at an average level.

4. Providing a good organizational level for the use of decision support systems in the Ministry.

5. The diversity of information systems that support decisions well with few types of decision support systems (DSS).

6. There are no statistically significant differences at the level of significance $\alpha \leq 0.05$ between the responses of respondents to the impact of decision support systems (DSS) on performance development due to age variables, job title and experience, while there are statistically significant differences at the level of $\alpha \leq 0.05$ due to gender variable, qualification, specialization and number of courses.

The study recommended building decision support systems on resonant scientific basis and making use of them at the ministry level as a whole, developing their applications and uses, supporting them in all decisions taken by the ministry, increasing support of senior management, and involving staff in developing decision support systems and constantly updating hardware and software. It also recommended that computers in the ministry should be linked with the other directorates within a network of communications, as well as linking the departments and directorates of the ministry with the global internet and activating the web programs.

Al-Qasimi (2009): Activating the business Re-engineering tasks from an ICT perspective: an integrative approach. The objective of the study was to activate the business Re-engineering tasks from an ICT perspective. The problem addressed in this study was how to make positive use of IT developments in business Reengineering programs. This question would be answered through a basic assumption that is (the use of IT tools contributes to improving the effectiveness of business Re-engineering programs). The study concluded with a number of results, the most important of which are:

1. Information is the hub around which processes are conducted. Information technology is one way of accomplishing the Re-engineering program. 
2. There is a relationship between decision support systems and Re-engineering and the need to support the adoption of ICTs in Re-engineering programs by senior executives.

3. Information and communication technology (ICT) helps enable Re-engineering management to operate independently and the need for communication and feedback in the application of IT tools to detect any developments, as well as the creation of (ICT) teams as an integral component of the Re-engineering team.

Alagha (2009) : An applied study for the Re-engineering of administrative processes in banks in Gaza Strip." The study aimed to identify the Re-engineering of processes in the banks in Gaza Governorates by identifying the impact and relationship of some factors affecting the Re-engineering of these factors (restructuring organizational structures, high technology capabilities, health and efficiency of banking processes, changing customer expectations and improving the overall quality standards). The sample of the study consisted of general managers, managers and heads of departments in the banks operating in the governorates of Gaza. The analytical descriptive method was selected and a questionnaire was used to collect the data. 150 questionnaires were distributed to the employees. The study concluded with a number of results, the most important of which are :

1. There is a statistically significant relationship between the Re-engineering of efficient administrative processes and the reconstruction of organizational structures.

2. There is a statistically significant relationship between Re-engineering of efficient administrative processes and high technology capabilities.

3. IT helps banks access valuable information that helps make decisions.

Attaran (2011) : Exploring the relationship between information technology and business process Reengineering.The study aimed to examine several relationships between information systems and the Reengineering processes by assuming that organizations wishing to reengineer their management processes should begin to develop their IT capabilities. It presented a summary of the role of information technology in the processes of Re-engineering processes through the study of several major US companies (Cisco, Dell, Intel and Sectron), which worked to adapt information technology to the success of the process of Re-engineering of administrative processes. The study concluded with a number of results, the most important of which are :

1. Information Technology (IT) can be the main obstacle for Re-engineering .

2. The resistance of IT staff is the reason for the failure of the application of Re-engineering processes rather than empowerment.

Zrigat (2010) : The impact of organizational learning in enhancing the Re-engineering aspects of administrative processes in Jordanian public institutions. The aim of the study was to identify the impact of organizational learning in enhancing the Re-engineering aspects of administrative processes in Jordanian public institutions. To achieve the objective of the study, a questionnaire was designed and developed for the purpose of collecting data and distributing it to the sample of 548. The SPSS program was used and the hypotheses were tested. The study concluded that here is an impact of the strategic and the organizational dimension of organizational learning in the Re-engineering of administrative processes.

The study recommended the need to create an organizational culture that promotes organizational learning strategies and to elevate these strategies to the desired high levels by developing the skills of employees and providing a clear strategic vision for public institutions and their objectives.

Flett \& Others (2010) : Re-engineering systems in general practice - a case study review. The study aimed to evaluate the general management practices of three health care institutions. The case studies of the United Kingdom by identifying the issues of existing systems, strategies and methods of work. The study concluded a number of results, the most important of which are:

1. There is a difference in the management of administrative processes among these institutions.

2. These organizations use an information system called the Recall Management System (DRM), a system that collects data from multiple sources and avoids problems that are expected to occur.

Arafat (2009) :Requirements specifications \& obstacles that forbidden development decision support system (DSS) in Palestinian Authority Ministries - (Gaza).This study aimed to assess the administrative requirements for the optimal use of decision support systems in the ministries of the Palestinian Authority from the directors' point of view. The study population comprised the Ministry of Education and the Ministry of Health. The researcher designed a special questionnaire for this research. The study concluded a number of results, the most important of which are: 
1. There is a good level of awareness among senior management of the importance of decision support systems (appropriate human resources system and adequacy of the organizational structure) in the institutions of the government sector in an acceptable level.

2. There are acceptable differences in the attitudes of managers towards assessing the administrative requirements for the optimal use of decision support systems in relation to age, experience and qualification in the institutions of the public sector.

\section{Methodology and procedures:}

\section{Research methodology:}

The researcher used the analytical descriptive method to describe and evaluate the role of decision support systems in the Re-engineering of administrative processes at Taif University. The study relied on data and information from various sources, including previous studies and articles in specialized periodicals, university transcripts, Arabic and foreign books and references related to the subject of the study. A questionnaire was used to provide data based on the objectives of the study and its variables with reference to previous studies, and taking the opinions of experts and specialists in this field. After analyzing the data and concluding the initial results, the study hypotheses were tested using appropriate statistical software (SPSS).

\section{The population and samples of the study:}

The study population consists of the administrators and academics working in administrative positions, which numbered (90) employees who were selected from Taif University with different specialties and administrative and functional ranks.

As for the sample of the study, the questionnaires were distributed to a large number of employees using decision support systems within the above mentioned categories. (90) Questionnaires were distributed. (84) Questionnaires were retrieved and (9) were excluded because they were not valid for statistical analysis. Questionnaires distributed to academics working in administrative positions were (28) and (47) administrators with a total of (75) questionnaires of (83.3\%), which is good for statistical analysis (Sakarn, 2010).

Table (1) : Frequency and percentage according to personal and professional variables (age, qualification and professional experience)

\begin{tabular}{||l|l|c|c|}
\hline Variable & Category & frequency & percentage\% \\
\hline \hline \multirow{4}{*}{ Age } & 30 years or less & 13 & $17.3 \%$ \\
\cline { 2 - 4 } & $31-40$ Year & 26 & $34.7 \%$ \\
\cline { 2 - 4 } & 41-50 Year & 19 & $25.3 \%$ \\
\cline { 2 - 4 } & 51 years or above & 17 & $22.7 \%$ \\
\hline \multirow{5}{*}{ Qualification } & Total & $\mathbf{7 5}$ & $\mathbf{1 0 0 \%}$ \\
\cline { 2 - 4 } & Diploma, intermediate or below & 5 & $6.7 \%$ \\
\cline { 2 - 4 } & Bachelor & 43 & $57.3 \%$ \\
\cline { 2 - 4 } & Master / Higher Diploma & 11 & $14.7 \%$ \\
\cline { 2 - 4 } & PhD & 16 & $21.3 \%$ \\
\hline \multirow{5}{*}{ Experience } & Total & $\mathbf{7 5}$ & $\mathbf{1 0 0} \%$ \\
\cline { 2 - 4 } & 5 years or less & 11 & $9.3 \%$ \\
\cline { 2 - 4 } & $6-10$ Years & 26 & $34.7 \%$ \\
\cline { 2 - 4 } & $11-15$ Year & 34 & $41.3 \%$ \\
\cline { 2 - 4 } & 16 years or above & $\mathbf{7 5}$ & $\mathbf{1 0 0} \%$ \\
\hline & Total & & \\
\hline
\end{tabular}

The results shown in the above table indicate that the characteristics of the sample are close to those of the surveyed population. For example, it is found that the percentage of the age group (41 - 50 years) was $34.7 \%$, which represents the largest share of workers at Taif University, which confirms that the university adheres to the youth age group. The percentage of those who are qualified at the bachelor level is very high at $93.3 \%$ of the study sample, which represents the largest percentage of the employees. The reason may be due to the employment systems to deal with administrative and academic systems at the university. The percentage of persons with practical experience of more than 16 years is $41.3 \%$, which is very high and shows that the university adheres to the employees of the youth category who are academically and administratively qualified, and who have high expertise in order to deal with the information systems used and which are reflected on dealing 
With modern management in order to restore administrative engineering processes, and this reflects the correct administrative and regulatory policies at the university.

\section{The study tool:}

The study relied on the questionnaire, in order to collect data, which was based on a number of items reflecting the problem of the study and its questions which were answered by the respondents. This questionnaire was divided into three sections, which were as follows:

Section I : A set of items about the personal and professional data of the sample of the study population.

Section II : The dimensions of the independent variable (Decision Support Systems (DSS)). This section was divided into four areas:

The first area : addressed the senior management support to use decision support systems and measured in items (1-5).

The second area : addressed the available requirements (hardware, software, human and organizational) for the use of decision support systems and measured in items (6 - 21).

The third area: addressed the decision support systems used and was measured in items (22-24).

The fourth area : addressed the dependent variable (The Re-engineering of administrative processes) and was measured in items $(25$ - 30).

The Likert scale was used so that each answer took relative importance, and the weights of those items were determined as follows: Strongly Disagree (1) score, Disagree (2) scores, Neutral (3) scores, Agree (4) score, and Strongly Agree (5) scores. The weights of the means and the level of significance were also measured by the following equation :-

$$
\text { Application Level }=\frac{\text { Upper Score - Lower Score }}{3}=\frac{5-1}{3}=1.33
$$

Therefore, it the value of the mean of the items is between $(1.00-2.33)$, it inumates that the level of the perceptions of the members of the sample is low. If the value of the mean is between $(2.34-3.66)$, this means that the level of the perceptions of the members of the sample is average, whereas if the value of the average of items is between (3.67 - 5.00), this indicates that the level of perceptions of the members of the study sample is high.

\section{The validity of the study tool : -}

The validity of the questionnaire means that the questions of the questionnaire measure what was designed it for. The researcher verified the veracity of the virtual questionnaire by presenting it to a group of specialized referees in the management information systems. The researcher responded to the opinions of the referees and made the necessary deletion and modification in the light of the referees' suggestions.

\section{The stability of the study tool :}

The researcher verified the stability of the study tool to ensure that the questionnaire measures the factors to be measured and verified. The internal consistency of all the items was tested by the Cronbach-Alpha $(\alpha)$ coefficient and, in practice, in regard to the administrative and human sciences if (Alpha $\geq 60$ ), it is then accepted (Sekaran, 2006).The results indicate that the stability coefficient for all dimensions of the questionnaire was (83.8\%), which is a high percentage. This indicates that the questionnaire is stable and valid for statistical analysis and scientific research. The following table shows the results of the stability tool of the study.

Table (2) : Coherence coefficient of the dimensions of the study questionnaire Cronbach - Alpha $(\alpha)$

\begin{tabular}{||l|l|c|c||}
\hline \hline Variables & Dimensions & Items No. & $(\boldsymbol{\alpha})$ Cronbach - Alpha \\
\hline \hline \multirow{3}{*}{ Independent Variable } & Senior management support & 4 & $84.3 \%$ \\
\cline { 2 - 4 } & $\begin{array}{l}\text { Available requirements } \\
\text { hardware, software, human and } \\
\text { organizational) }\end{array}$ & 16 & $86.7 \%$ \\
\cline { 2 - 4 } & Decision support systems used & 4 & $83.9 \%$ \\
\hline Dependent variable & Management Processes Engineering & 8 & $85.6 \%$ \\
\hline Total & & 24 & $\mathbf{8 5 . 8 7 \%}$ \\
\hline
\end{tabular}




\section{Statistical Processing:}

In order to answer the questions of the study and to test the validity of hypotheses, descriptive and analytical statistical methods were used by using statistical program (SPSS). The statistical methods used descriptive statistical measures included frequency and percentages, mean and standard deviation (Mahmoud and Salah, 2009). Cronbach - Alpha $(\alpha)$ was also used to confirm the stability of the items of the questionnaire, (F) test to verify the significance of the role of the study variables, Pearson Correlation Coefficient, One sample $\mathrm{t}$ - Test, simple regression test (Alarudi, Fathi, 2011), and the One Way Analysis of Variance - ANOAV test to see if there were statistically significant differences between three or more sets of data.

\section{Procedural definitions :}

\section{The Independent variable ( Decision Support Systems (DSS)) :}

* Decision support systems: are basic systems based on interactive support using a software package that allows the decision maker to deal directly with the computer to obtain effective information in the structured and semi-structured decision-making processes. DSS helps decision-maker solve unstructured, tactical, and strategic management problems using data and models (Al- Shawabkeh, 2015). The independent variable is divided into:

- Hardware requirements : The devices and networks used in the information system, including I / O and CPU.

- Software requirements : The software package that is used to run and manage system devices in addition to the software applications used in the performance of work.

- Human requirements : The body responsible for maintaining the system and networks to address the problems faced by users during the use of the automated information system.

- Organizational requirements : The support of senior management to use the information system and the ability of the system to provide information to users without organizationalrestrictions.

\section{The dependent variable (Business Process Re-Engineering Concept) :}

It means a substantial change in organizational processes through the use of information technology and optimal use to achieve substantial improvements in quality, performance and productivity. Its dimensions include (the commitment and satisfaction of the senior management of the philosophy of administrative processes of communication, administrative empowerment and the culture of the organization), and an administrative approach that helps managers face competition through building new visions and mission that help propose a new series of strategies and their application (Box \& Platts, 2015).

The independent variable : Considered the dimensions of the decision support systems.

* The (T) test was used to determine whether the average of the approval level reached the neutral (3) level or not, or it increased or decreased.

\section{This variable has been divided into four areas :}

The first area : senior management support for the use of decision support systems and measured in the following items (1-4) :

1. Senior management relies on decision support systems of (DSS) to make decisions.

2. Senior management provides the necessary hardware and software for the use of (DSS).

3. Senior management is concerned with decision support systems of (DSS) as part of the overall organizational development process.

4. Senior management supports training courses in the development of (DSS).

Table (3) : The mean, the standard deviation, the (t- test) and the significance level for the estimation of the members of the study sample

\begin{tabular}{|c|c|c|c|c|c|}
\hline Item No. & Mean & St. Dev. & t- test value & Sig. & Rank \\
\hline \hline 1 & 4.32 & 0.903 & 12.7 & 0.000 & 2 \\
\hline 2 & 4.01 & 1.053 & 8.23 & 0.000 & 4 \\
\hline 3 & 4.59 & 0.572 & 24.04 & 0.000 & 1 \\
\hline 4 & 4.04 & 0.907 & 9.93 & 0.000 & 3 \\
\hline In General & 4.24 & 0.000 & 14.83 & & \\
\hline
\end{tabular}


The results of the analysis shown in table (3) show that the results of the senior management support test for the use of decision support systems achieved a high mean of 4.24 and a standard deviation of 0.722 , which falls within the very high grade. Item 3 achieved the highest mean of 4.59, where senior management is concerned with decision support systems as part of the overall organizational development processes, while item 2 achieved the lowest mean of 4.01. To verify the accuracy of the estimation of the members of the study sample based on the mean, $t$ test and its related significance level were used and it was found that the value of the calculated ( $t$ ) was 14.83 and its significance level is 0.000 , which is statistically significant at the level of $\alpha \leq 0.05$, indicating the significance of the estimation based on the mean. In general, the first level of senior management support for the use of decision support systems is high.

The second area : The available resources (hardware, software, human and organizational) were divided into four dimensions as follows :

The first dimension : hardware resources available and measured in the following items (5 - 8):

5. The number of computers fits the number of employees, and their capacity is sufficient to store the data.

6. University provides the means to enter data which are appropriate to the needs of the work.

7. Output methods suit the requirements of work.

8. The computer network located in the university is modern, fast and suitable for business needs.

Table (4): The mean, the standard deviation, the (t- test) and the significance level for the estimation of the sample of the study population

\begin{tabular}{|c|c|c|c|c|c|}
\hline Item No. & Mean & St. Dev. & t- test value & Sig. & Rank \\
\hline 5 & 3.69 & 1.701 & 3.53 & 0.000 & 4 \\
\hline 6 & 3.91 & 0.975 & 8.05 & 0.000 & 3 \\
\hline 7 & 4.24 & 0.871 & 12.46 & 0.000 & 2 \\
\hline 8 & 4.25 & 0.522 & 20.78 & 0.000 & 1 \\
\hline In General & 4.03 & 0.835 & 10.65 & & \\
\hline
\end{tabular}

The results of the analysis shown in table (4) indicate that the results of testing the available hardware resources for the use of decision support systems achieved a high mean of 4.03 and a standard deviation of 0.835 , which falls within the very high grade. Item 8 achieved the highest mean of 4.25 , where the computer network provided by the university is updated and quick enough to meet the needs of the work. While item 5 achieved the lowest mean of 3.69. In order to verify the accuracy of the estimation of the members of the study sample based on the mean, $t$ test was used and the level of significance associated with it, where the calculated value of $t$ is 10.65 and its significance level is 0.000 which is statistically significant at the level of $\alpha \leq 0.05$ indicating the significance of the estimation based on the mean. In general, the level of the available hardware resources dimension is high.

The second dimension : Available software resources and measured in items (9-12) :

9. There are specialized programs for decision support systems in the university which are compatible with the devices used.

10. Software used help employees cover all the activities of the university.

11. Software are modern, easy to learn and commensurate with the requirements of work.

12. Computer programs are compatible with the network used in the work.

Table (5) : The mean, the standard deviation, the (t- test) and the significance level for the estimation of the sample of the study population

\begin{tabular}{|c|c|c|c|c|c||}
\hline \hline Item No. & Mean & St. Dev. & t- test value & Sig. & Rank \\
\hline \hline 9 & 3.41 & 1.396 & 2.56 & 0.000 & 4 \\
\hline 10 & 4.29 & 0.802 & 13.97 & 0.000 & 1 \\
\hline 11 & 3.89 & 1.085 & 7.13 & 0.000 & 3 \\
\hline 12 & 3.99 & 0.604 & 14.15 & 0.000 & 2 \\
\hline In General & 3.89 & 0.617 & 12.59 & & \\
\hline
\end{tabular}


The results of the analysis shown in table (5) indicate that the results of the test of the available software requirements for the use of decision support systems achieved a high mean of 3.89 and a standard deviation of 0.917 which is within the high degree. Item 10 achieved the highest mean of 4.29 where there are specialized programs for the decision support systems in the university and corresponds to the devices that are used, while item 9 achieved a lower mean of 3.41. In order to verify the accuracy of the estimation of the members of the study sample based on the calculation, $t$ test was used and significance level. It is found that the calculated value of $t$ is 12.59 and its significance level is 0.000 which is statistically significant at the level of $\alpha \leq 0.05$ indicating the significance of the estimate based on the mean. In general, the available software requirements dimension is high.

The third dimension : Available human resources and measured in items (13-16) :-

13. There is a technical department responsible for decision support systems (DSS) with highly specialized personnel in technology.

14. The staff of the relevant technical department understands the needs of the users of these programs.

15. There is a direct contact with the technical department responsible for the system and programs.

16. The technical department deals with the problems and queries faced by users of the programs and the network.

Table (6) : The mean, the standard deviation, the (t- test) and the significance level for the estimation of the sample of the study population

\begin{tabular}{|c|c|c|c|c|c|}
\hline Item No. & Mean & St. Dev. & t- test value & Sig. & Rank \\
\hline \hline 13 & 3.89 & 0.815 & 9.49 & 0.000 & 3 \\
\hline 14 & 4.12 & 1.102 & 8.78 & 0.000 & 2 \\
\hline 15 & 3.88 & 1.185 & 6.43 & 0.000 & 4 \\
\hline 16 & 4.16 & 0.886 & 11.34 & 0.000 & 1 \\
\hline In General & 4.01 & 0.781 & 11.24 & & \\
\hline
\end{tabular}

The results of the analysis shown in table (6) indicate that the results of the available human resources test for the use of decision support systems achieved a high mean of 4.01 and a standard deviation of 0.781 , which is within the high range. Item 16 achieved the highest mean of 4.16, where the relevant technical section deals with the problems and queries facing the users of the programs and the network, while item 15 achieved a lower mean of 3.88. In order to verify the accuracy of the assessment of the members of the study sample based on the calculation, $t$ test was used and the level of significance related to it. It is found that the calculated value of $t$ is 11.24 and its significance level is 0.000 which is statistically significant at the level of $\alpha \leq 0.05$ indicating the significance of the estimate based on the mean. In general, the available human resources level is high.

The fourth dimension : The available organizational resources and measured in the following items (17-20) :

17. Senior management is concerned with the views and suggestions of staff on the use of decision support systems (DSS).

18. Senior management provides appropriate training programs that serve decision support systems (DSS).

19. The organizational structure allows for easy flow of information between different administrative levels, depending on their needs.

20. Decision support systems (DSS) facilitate the use of administrative communication between different departments within the university.

Table (7) : The mean, the standard deviation, the (t- test) and the significance level for the estimation of the sample of the study population

\begin{tabular}{|c|c|c|c|c|c||}
\hline Item No. & Mean & St. Dev. & t- test value & Sig. & Rank \\
\hline \hline 17 & 4.03 & 0.34 & 19.15 & 0.000 & 4 \\
\hline 18 & 4.13 & 1.189 & 8.25 & 0.000 & 2 \\
\hline 19 & 4.52 & 0.578 & 22.78 & 0.000 & 1 \\
\hline 20 & 4.05 & 0.634 & 14.38 & 0.000 & 3 \\
\hline In General & 4.18 & 0.467 & 21.93 & & \\
\hline \hline
\end{tabular}


The results of the analysis shown in table (7) indicate that the results of the available organizational resources test for the use of decision support systems achieved a high mean of 4.18 and a standard deviation of 0.467 , which is within the high range. Item 19 achieved the highest mean of 4.52. The organizational structure allows easy flow of information between the different administrative levels according to their needs, while item 17 achieved the lowest mean of 4.03. In order to verify the accuracy of the estimation of the members of the study sample based on the mean, the t-test was used and the related significance level where it is shown that the calculated t value of is 21.93 and its significance level is 0.000 which is statistically significant at the level of $\alpha \leq 0.05$ indicating the significance of the estimate based on the mean. In general, the available organizational resources level is high.

The third area : Types of decision support systems; used and measured in items (21-24) :

21. Computer software used achieve repeated processes.

22. Computer software have the ability to retrieve information quickly.

23. Computer software have the ability to prepare periodic reports covering aspects of work and preparing special reports.

24. Computer software are modern and contribute to the strategic planning of the university.

Table (8) : The mean, the standard deviation, the (t- test) and the level of significance of the sample members

\begin{tabular}{|c|c|c|c|c|c|}
\hline Item No. & Mean & St. Dev. & t- test value & Sig. & Rank \\
\hline \hline 21 & 4.23 & 0.649 & 16.37 & 0.000 & 2 \\
\hline 22 & 4.12 & 1.078 & 9.01 & 0.000 & 3 \\
\hline 23 & 3.95 & 0.567 & 14.46 & 0.000 & 4 \\
\hline 24 & 4.57 & 0.498 & 27.37 & 0.000 & 1 \\
\hline In General & 4.22 & 0.538 & 19.59 & & \multicolumn{1}{|c|}{} \\
\hline
\end{tabular}

The results of the analysis shown in table (8) indicate that the results of the test of the types of decision support systems for the use of decision support systems achieved a high mean of 4.22 and a standard deviation of 0.538 , which is within the high range. Item 24 achieved the highest mean of 4.57, where modern computer programs contribute to the strategic planning of the university, while item 23 achieved a minimum mean of 3.95 . To verify the accuracy of the assessment of the members of the study sample based on the mean, it is found that the value of the calculated $t$ is 19.59 and the significance level of 0.000 which is statistically significant at the significance level of $\alpha \leq 0.05$, indicating the significance of the estimate based on the mean. In general, the level of type of decision support systems used is high.

Table (9): shows the correlation coefficient between senior management support for the use of decision support systems and the Re-engineering of administrative processes

\begin{tabular}{|c|c|c|c|}
\hline Area No. & Area Name & $\begin{array}{r}\text { Pearson correlation } \\
\text { coefficient }\end{array}$ & $\begin{array}{l}\text { Probability } \\
\text { Value (sig.) }\end{array}$ \\
\hline First area & Senior management support & 0.710 & $0.000 *$ \\
\hline \multirow{4}{*}{ Second Area } & Hardware resources & 0.885 & $0.000 *$ \\
\hline & Software resources & 0.810 & $0.000 *$ \\
\hline & Human resources & 0.623 & $0.000 *$ \\
\hline & Organizational resources & 0.755 & $0.000 *$ \\
\hline Third Area & Types of decision support & 0.698 & $0.000 *$ \\
\hline
\end{tabular}

correlation coefficient between independent variable areas (senior management support, hardware, software, human and organizational resources) and types of decision support systems used for the use of decision support systems and Re-engineering of administrative processes respectively) are $(0.710,0.885,0.810,0.755,0.698)$ and that the probability value (sig.) is equal to all areas (0.000), which is below the significance level of 0.05 . Therefore, there is a statistically significant relationship at the significance level of $\alpha \leq 0.05$ between the three areas for the use of decision support systems and Re-engineering of administrative processes at Taif University.

The fourth area : Re-engineering processes measured in items (25-30) :

25. The university administration is aware of the concept of Re-engineering processes, which ensures progress and development. 
26. The strengths, weaknesses, opportunities and threats facing the university are analyzed.

27. The university's management policies guide decision making towards change and performance development.

28. The University's administrative policies generate trust among staff and reduce uncertainty in decisionmaking.

29. The organizational structure of the university helps speed up administrative communication and achieve goals.

30. The use of IT leads to the ability to redesign its Re-engineering of its administrative processes.

Table (10) : The mean, the standard deviation, the $t$ test, and the level of significance of the sample members

\begin{tabular}{|c|c|c|c|c|c|}
\hline Item No. & Mean & St. Dev. & t- test value & Sig. & Rank \\
\hline \hline 25 & 4.12 & 0.327 & 29.65 & 0.000 & 4 \\
\hline 26 & 4.13 & 1.119 & 16.27 & 0.000 & 3 \\
\hline 27 & 4.49 & 0.795 & 8.27 & 0.000 & 1 \\
\hline 28 & 4.36 & 0.510 & 23.07 & 0.000 & 2 \\
\hline 29 & 3.65 & 1.289 & 4.39 & 0.000 & 5 \\
\hline 30 & 3.63 & 1.136 & 4.78 & 0.000 & 6 \\
\hline In General & 4.06 & 0.596 & 15.46 & & \\
\hline
\end{tabular}

The results of the analysis in table (10) indicate that the results of the Re-engineering of administrative process for the use of decision support systems achieved a high mean of 4.06 and a standard deviation of 0.596, which is within the high range. Item 27 achieved the highest mean of 4.49 as the university's administrative policies guide the decision-making process towards change and performance development. Item 30 achieved the lowest mean of 3.63. To verify the accuracy of the assessment of the members of the study sample based on the calculation, and the level of significance related to it, it is found that the value of the calculated $t$ is 15.46 and the level of significance is 0.000 which is statistically significant at the level of $\alpha \leq 0.05$, which indicates the significance of the estimate based on the mean. In general, the Re-engineering of administrative process is high.

\section{Testing hypotheses :}

\section{The first main hypothesis :}

There is no statistically significant relationship at the level of $\alpha \leq 0.05$ between senior management support and re-engineering of administrative processes at Taif University.

To test this hypothesis, simple regression was used as follows :

Table (11) : shows the results of simple regression analysis of senior management support systems for the use of decision support systems

\begin{tabular}{|c|c|c|c|c|c|c|c|c|c|}
\hline $\mathrm{R}$ & $\mathrm{R}^{2}$ & $\overline{\mathrm{F}}$ & $\mathrm{df}$ & & *Sig & $\beta$ & $\mathrm{T}$ & *Sig & Decision \\
\hline \multirow{3}{*}{$0.710^{\mathrm{a}}$} & \multirow{3}{*}{0.505} & \multirow{3}{*}{74.35} & Regression & 1 & \multirow{3}{*}{$0.000^{\mathrm{b}}$} & \multirow{3}{*}{$0.583^{\mathrm{a}}$} & \multirow{3}{*}{8.623} & \multirow{3}{*}{$0.000^{\mathrm{b}}$} & \multirow{3}{*}{$\begin{array}{l}\text { Hypothesis } \\
\text { rejected }\end{array}$} \\
\hline & & & Residual & 73 & & & & & \\
\hline & & & Total & 74 & & & & & \\
\hline
\end{tabular}

The results of the analysis in table (11) indicate showed that the value of the sig. level is 0.000 , which means that there is a statistically significant effect of the senior management support for the use of decision support systems and the Re-engineering of administrative processes at Taif University. The correlation coefficient $\mathrm{R}=0.710$ at the level of $\alpha \leq 0.05$, and the R2 $=0.505$ which means that $50.5 \%$ of the changes in the Re-engineering of administrative processes result from the senior management support systems for the use of decision support systems.The value of the degree of influence is $\beta=0.583$. This means that there is one-degree increase in the level of the senior management support systems for the use of decision support systems leads to an increase in the Reengineering of the administrative processes at Taif University with a value of $58.3 \%$. The significance of this effect confirms the value of calculated $\mathrm{F}$ at 74.35 which is statistically significant at the level of $\alpha \leq 0.05$, and this confirms the invalidity of the first main hypothesis.

Decision: - Rejecting the current nihilistic hypothesis and accepting the alternative hypothesis.

The second main hypothesis : 
There is no statistically significant relationship at the level of $\alpha \leq 0.05$ between the available resources (hardware, software, human and organizational) combined together for the use of decision support systems in the Reengineering of administrative processes at Taif University.

To test this hypothesis, multi regression is used as follows :

Table (12) : shows the results of the simple regression analysis of the effect of available sources (hardware, software, human and organizational)

\begin{tabular}{|c|c|c|c|c|c|c|c|c|c|}
\hline$\overline{\mathrm{R}}$ & $\overline{\mathrm{R}^{2}}$ & F & df & & $*$ Sig & $\beta$ & & $\mathrm{T}$ & *Sig \\
\hline \multirow{4}{*}{$0.913^{\mathrm{a}}$} & \multirow{4}{*}{0.833} & \multirow{4}{*}{87.54} & Regression & 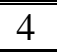 & \multirow{4}{*}{$0.000^{\mathrm{b}}$} & Hardware Req. & 0.546 & 5.682 & \multirow{4}{*}{$0.000^{\mathrm{b}}$} \\
\hline & & & Residual & 70 & & Software Req. & 0.341 & 4.105 & \\
\hline & & & \multirow{2}{*}{ Total } & \multirow{2}{*}{74} & & Human Req. & 0.426 & 5.623 & \\
\hline & & & & & & Organizational Req. & 0.582 & 4.753 & \\
\hline
\end{tabular}

The results of the analysis in Table (12) indicate that there is a statistically significant effect on the available resources (hardware, software, human and organizational) for the use of decision support systems and the Reengineering of administrative processes at Taif University. The simple correlation coefficient $\mathrm{R}=0.913$ at the level of $\alpha \leq 0.05$ and $\mathrm{R}^{2}=0.833$. This means that $83.3 \%$ of the changes in the Re-engineering of the administrative processes resulted from the change in the available resources, and the degree of influence of the hardware resources $\beta=0.546$, the value of the degree $\mathrm{B}=0.341$, the value of the degree of impact of human resources $\beta=0.426$ and the value of the degree of influence of the organizational resources $\beta=0.583$. This means that there is one-degree increase in the level of attention to the available resources leads to an increase in the improvement of Re-engineering of administrative process by $54.6 \%$ for hardware resources, and $34.1 \%$ for software resources, $42.6 \%$ for human resources and $58.2 \%$ for organizational resources. The significance of this effect confirms the calculated $F$ value of 87.54 which is a function at $\alpha \leq 0.05$ and this confirms that the second main hypothesis is incorrect.

\section{Decision :}

Rejecting the current nihilistic hypothesis and accepting the alternative hypothesis.

\section{The third main hypothesis :}

There is no statistically significant relationship at the level of $\alpha \leq 0.05$ for the types decision support systems used in the Re-engineering of administrative processes at Taif University

To test this hypothesis, simple regression is used as follows :

Table (13) : shows the results of the simple regression analysis of the effect of available sources (hardware, software, human and organizational)

\begin{tabular}{|c|c|c|c|c|c|c|c|c|c|}
\hline $\mathrm{R}$ & $\mathrm{R}^{2}$ & $\bar{F}$ & \multicolumn{2}{|l|}{$\mathrm{df}$} & . ${ }^{*} \mathrm{Sig}$ & $\beta$ & $\mathrm{T}$ & *Sig & Decision \\
\hline \multirow{3}{*}{$0.689^{\mathrm{a}}$} & \multirow{3}{*}{0.485} & \multirow{3}{*}{69.41} & Regression & 1 & \multirow{3}{*}{$0.000^{\mathrm{b}}$} & \multirow{3}{*}{$0774^{\mathrm{a}}$} & \multirow{3}{*}{8.33} & \multirow{3}{*}{$0.000^{\mathrm{b}}$} & \multirow{3}{*}{$\begin{array}{c}\text { Hypothesis } \\
\text { rejected }\end{array}$} \\
\hline & & & \begin{tabular}{|l|} 
Residual \\
\end{tabular} & 73 & & & & & \\
\hline & & & Total & 74 & & & & & \\
\hline
\end{tabular}

The results of the analysis in table (13) indicate that the value of the sig level is 0.000 , which means that there is a statistically significant effect between the types of decision support systems for the use of decision support systems and the Re-engineering of administrative processes at Taif University. The correlation coefficient $\mathrm{R}=$ 0.698 at $\alpha \leq 0.05$ and $\mathrm{R} 2=0.487$, i.e. $48.7 \%$ of the changes in the Re-engineering of administrative processes result from the availability of the type of decision support systems used.The value of the degree of influence is $\beta=$ 0.774. This means that there is one-degree increase in the level of the type of decision support systems which leads to an increase in the Re-engineering of administrative processes by $77.4 \%$. The significance of this effect is the calculated $F$ value of 69.41 which is statistically significant at the level of $\alpha \leq 0.05$. Thus, the third main hypothesis is incorrect. 


\section{The decision :}

Rejecting the current nihilistic hypothesis and accepting the alternative hypothesis.

\section{The fourth hypothesis :}

There are no statistically significant differences between the responses of the respondents at the level of $\alpha \leq 0.05$, the role of decision support systems and the Re-engineering of administrative processes at Taif University due to personal and functional variables (age, qualification and functional experience).

To test this hypothesis, one way ANOVA is used to test the following sub-hypotheses:

\section{The first sub - hypothesis :}

There are no statistically significant differences at the level of $\alpha \leq 0.05$ in the respondents' perceptions of the role of decision support systems and Re-engineering of administrative processes at Taif University due to the age variable.

Table (14) : Shows ANOVA Test Results

\begin{tabular}{||l|l|l|l|l|l|l||}
\hline & \multicolumn{1}{|c|}{ Sum of Squares } & Mean Square & \multicolumn{1}{|c|}{ df } & F & Sig. & Decision \\
\hline \hline Between Groups & 0.325 & 0.108 & 3 & \multirow{2}{*}{1.269} & 0.828 & $\begin{array}{l}\text { Hypothesis } \\
\text { accepted }\end{array}$ \\
\hline Within Groups & 26.002 & 0.366 & 71 & 74 & & \\
\hline Total & 26.327 & & 74 &
\end{tabular}

The results shown in table (14) indicate that there are no statistically significant differences, based on the level of significance (sig), which is $(0.828)$, which is greater than $(\alpha \leq 0.05)$ and $F$ value is (1.269). This confirms that the first sub-hypothesis is incorrect.

The decision : Accepting the hypothesis in its current nihilistic form.

\section{The second sub - hypothesis :}

There are no statistically significant differences at the level of $\alpha \leq 0.05$ in the respondents' perceptions of the role of decision support systems and Re-engineering of administrative processes at Taif University due to the qualification variable.

Table (15) : Shows ANOVA Test Results

\begin{tabular}{||l|c|c|c|c|c|l||}
\hline & Sum of Squares & Mean Square & df & F & Sig. & Decision \\
\hline \hline Between Groups & 1.722 & 0.574 & 3 & \multirow{2}{*}{1.656} & 0.184 & $\begin{array}{l}\text { Hypothesis } \\
\text { accepted }\end{array}$ \\
\hline Within Groups & 24.606 & 0.347 & 71 & 74 & &
\end{tabular}

The results shown in table (15) indicate that there are no statistically significant differences, based on the level of significance (sig), which is $(0.184)$, which is greater than $(\alpha \leq 0.05)$ and $F$ value is (1.269). This confirms that the second sub-hypothesis is incorrect.

The decision : Accepting the hypothesis in its current nihilistic form.

\section{The third sub - hypothesis :}

There are no statistically significant differences at the level of $\alpha \leq 0.05$ in the respondents' perceptions of the role of decision support systems and Re-engineering of administrative processes at Taif University due to the functional experience variable.

Table (16) : Shows ANOVA Test Results

\begin{tabular}{||l|c|c|c|c|c|l||}
\hline & Sum of Squares & Mean Square & df & F & Sig. & Decision \\
\hline \hline Between Groups & 1.137 & 0.379 & 3 & & \multirow{2}{*}{0.368} & $\begin{array}{l}\text { Hypothesis } \\
\text { accepted }\end{array}$ \\
\hline Within Groups & 25.191 & 0.355 & 71 & 1.068 & 0.34 & \\
\hline Total & 26.327 & & 74 & &
\end{tabular}

The results shown in table (16) indicate that there are no statistically significant differences, based on the level of significance (sig), which is (0.368), which is greater than $(\alpha \leq 0.05)$ and $\mathrm{F}$ value is $(1.068)$. This confirms that the third sub-hypothesis is incorrect. 


\section{The decision :}

Accepting the hypothesis in its current nihilistic form

\section{The results :}

1. The level of senior management support for the use of decision support systems is high.

2. The level of the available resources (hardware, software, human and organizational) is high.

3. The level of the type of decision support systems used is high.

4. The level of Re-engineering of administrative processes is high.

5. There is a statistically significant relationship at $\alpha \leq 0.05$ level between senior management support for the use of decision support and the Re-engineering of administrative processes.

6. There is a statistically significant relationship at $\alpha \leq 0.05$ level between (hardware, software, human and organizational resources) for the use of decision support and the Re-engineering of administrative processes.

7. There is a statistically significant relationship at $\alpha \leq 0.05$ level between type of decision support systems for the use of decision support and the Re-engineering of administrative processes.

8. There are no statistically significant differences between the responses of the respondents at the level of $\alpha \leq$ 0.05 on the role of decision support systems in the Re-engineering of administrative processes at Taif University due to the variables of age, qualification and functional experience.

\section{Recommendations :}

The study recommended the following :

1. Developing IT infrastructure in general and decision support systems in particular.

2. Increasing the attention to the available hardware and software resources to use decision support systems through the continuity of keeping up with the modern technologies.

3. Increasing the attention to the human available resources to use decision support systems by providing specialized training programs for administrators and academics.

4. Increasing the attention to the available organizational resources to use decision support systems through an independent unit of decision support systems which is directly affiliated with the university administration.

5. Connecting computers in the university with the other units within a communication network, as well as linking the departments and colleges of the university with the global internet and activating the web programs.

\section{References}

Mustafa, Aldahrawi : Computerized Information Systems. Aljami'ah Aljadeda Publishing House, Alexandria, 2010.

Althobaiti, Aqeel : An Introduction to the Integrated Methodology of TQM. $1^{\text {st }}$ ed., Amman: Wael Publishing House, 2012.

Alkasasba, Mohammed : The Role of Information Technology in Re-engineering Business Processes: A Field Study on the ICT Company in Jordan. PhD thesis, Amman Arab University, Jordan, 2004.

Hammer, Michael, Shamby, James : Trans. Osman, Shams Eddine, Re-engineering of Administrative Processes, Arab Scientific Advertising Company, Shuaa, Cairo, 2012.

Alshawabka, Adnan Awad : Decision Support Systems, Al-Zahraa Publishing and Distribution House, Riyadh, 2015.

Al-Humaidi, Najm Abdullah, Samarra'i, Salwa : Management Information Systems. Wael Publishing House, Jordan, 2009.

Yassine, Ghaleb : Decision Support Systems, $1^{\text {st }}$ ed., Al-Manahij House, Amman, 2006.

Alsabbagh, Imad : Computer in Business Administration - Systems - Applications - Management. $1^{\text {st }}$ ed., AlThaqafa Publishing House, Amman, 2000.

Alkurdi, Manal Mohamed : Management Information Systems - Basic Concepts and Applications, University House, Alexandria, 2013.

Al-Sulami, Ali : Total Quality Management and Qualification Requirements for ISO 9000, Ghareeb Publishing House, Cairo, 2009.

Alharbi, Mohammed : Creative Management in Higher Education Institutions in Saudi Arabia, 2008. 
Malkawi, Nazem Mahmoud : The Impact of Decision Support Systems and Business Intelligence and their Impact on Improving Decision Making at King Abdullah Hospital. Faculty of Economics, Journal of Economic Studies, Issue 1, Irbid, 2014.

Ramadhan, Fadwa : The Impact of Using Decision Support Systems on Developing Performance: An Empirical Study on the Ministry of Education, Gaza Strip Governorates, Unpublished Master Thesis, Islamic University, Gaza, 2010.

Al-Qassimi, Mohammed : Activating the Business Re-engineering Missions from the ICT Perspective: An Integrated Approach, A Paper Submitted for the Third Scientific Conference of the Faculty of Administrative Sciences, Applied Science University, Entitled Managing Business Organizations Contemporary Global Challenges, Amman, 2009.

Agha, Yousef : An Applied Study for the Re-engineering of Administrative Processes in Banks in Gaza Strip, 2009.

Al-Aroudi, Fathi, Al-Atom, Mufid : Statistical Methods - part 1, $1^{\text {st }}$. ed., Jordan, Al-Manahij Publishing House, 2011.

Hammer, Michael and Champ, James: Re-engineering the Corporation. A Manifesto for Business Revolution, Harper Business, 2012.

Bernard, C. Riemann : Decision Support Systems - Strategic Management Tools for the Eighties، Business Horizons. Vol. 28, No.5,.2009.

Gupta, Uma. G: Information Systems : success in the 21st. century N.J: premise-ha 2000.

Alter, Steven : Information system $4^{\text {th. }}$ Ed. N.Y: The Benjamin/ Cummings publishing company, inc. 2002.

Haag \& Others : Management Information Systems for Information Age, 3ed. 2002.

Box, S., \& Plats, K.: Business process management, establishing and maintaining project alignment, Business Process Management Journal, Vol. 11 No. 4, 2013.

Attaran' Mohsen : Exploring the relationship between IT and business process Re-engineering ، Information \& Management journal NO. 41, 2011.

Zrigat, Kh., \& Kh., Y. : The Impact of Organizational Learning in Enhancing the Re-Engineering aspects of administrative processes in Jordanian public Institutions. University of Jordan, Journal of Business Administration, Vol.6 Issue 3, 2010.

Flett, P., \& Curry P. : Re-engineering systems in General practice - A case study review, International Journal of Information Management journal, No. 28, 2010.

Arafat, Moh :Requirements Specifications \& Obstacles that ForbiddenDevelopment Decision Support System (DSS) in Palestinian Authority Ministries - Gaza, 2009.

Sekaran, Uma : Research Method for Buildings, A skill buildings approach. 4th. ed. N.Y, john Willy \& sons, Inc., 2006. 